\title{
BMJ Open Factors associated with quality of life and work ability among Finnish municipal employees: a cross- sectional study
}

\author{
Elina Bergman (10 , ${ }^{1}$ Eliisa Löyttyniemi, ${ }^{2}$ Saana Myllyntausta, ${ }^{3}$ Päivi Rautava, ${ }^{3,4}$ \\ Päivi Elina Korhonen ${ }^{1,5}$
}

To cite: Bergman E, Löyttyniemi E, Myllyntausta S, et al. Factors associated with quality of life and work ability among Finnish municipal employees: a crosssectional study. BMJ Open 2020;10:e035544. doi:10.1136/ bmjopen-2019-035544

- Prepublication history for this paper is available online. To view these files, please visit the journal online (http://dx.doi org/10.1136/bmjopen-2019035544).

Received 05 November 2019 Revised 15 May 2020 Accepted 12 August 2020

\section{Check for updates}

(C) Author(s) (or their employer(s)) 2020. Re-use permitted under CC BY-NC. No commercial re-use. See rights and permissions. Published by BMJ.

${ }^{1}$ General Practice, University of Turku, Turku, Finland

${ }^{2}$ Department of Biostatistics, University of Turku, Turku,

Finland

${ }^{3}$ Department of Public Health, University of Turku, Turku, Finland

${ }^{4}$ Clinical Research Centre, Turku University Hospital, Turku, Finland

${ }^{5}$ Central Satakunta Health Federation of Municipalities, Harjavalta, Finland

Correspondence to

Dr Elina Bergman; elkaro@utu.fi

\section{ABSTRACT}

Objectives Quality of life (QoL) and work ability are elementary parts in defining the well-being of an employed person. The aim of this study was to demonstrate factors associated with QoL and self-reported work ability among public sector employees, while taking into account several confounding factors, including sleep quality, occupational stress and psychological symptoms.

Methods A cross-sectional study was conducted in Finland among 710 employees (89\% women, mean age $49(S D=10)$ years) from 10 municipal work units in 2015. Information about the participants was collected by physical examination, self-administered questionnaire and from medical history. QoL was assessed with the EUROHIS-Quality of Life 8-item index and work ability with the Work Ability Score (WAS).

Results The EUROHIS-QOL mean score among all participants was 4.07 (95\% Cl 4.03 to 4.11). QoL was positively associated with good sleep quality, cohabiting, university-level education and lower body mass index (BMI), and negatively associated with occupational stress, depression and/or anxiety and disease burden. Work ability was reported good or excellent by $80 \%$ of the participants and the WAS mean score among all participants was 8.31 (95\% Cl 8.21 to 8.41$)$. Work ability was positively associated with good sleep quality, younger age, lower BMl and university-level education, and negatively associated with occupational stress and disease burden.

Conclusions 0ccupational stress and self-reported sleep quality were strongly associated with both QoL and work ability among Finnish public sector employees. These findings highlight the need for screening and handling of work stress and sleep problems in occupational and primary healthcare.

\section{INTRODUCTION}

Quality of life (QoL) and work ability are elementary outcomes in defining the wellbeing of an employed person. Both of these can be affected by numerous conditions, including physical and mental health, ${ }^{12}$ occupational stress, ${ }^{34}$ sleep quality, ${ }^{56}$ psychosocial risk factors and environmental aspects. ${ }^{7}$ Many of these can be measured reliably by
Strengths and limitations of this study

- Several aspects associated with the employees quality of life and work ability could be taken into account.

- The participants completed all questionnaires at home before the examination was performed.

- Psychological symptoms were assessed with wellvalidated instruments.

- Any causality cannot be determined due to the cross-sectional nature of the study.

- The response rate of the study was moderate at most, which is a common limitation in email surveys.

evaluating the persons' perceptions about the condition with self-reported assessment tools. ${ }^{18-13}$ In our previous study, especially selfreported sleep quality was strongly associated with QoL among public sector employees. ${ }^{14}$

QoL and work ability have been studied also previously in currently employed populations, but most of the studies have concentrated on a specific occupational group or employees suffering from a certain medical condition. ${ }^{21516}$ To our knowledge, there is a gap of information about factors associated with QoL and work ability, studied simultaneously among apparently healthy public sector employees. Public sector is a large employer sector in the Scandinavian countries, and it would be important to recognise the factors associated with the well-being of the employees in municipal work places.

The aim of this study was to demonstrate factors associated with QoL and selfreported work ability among public sector employees, while taking into account several confounding factors, including psychological symptoms, sleep quality and occupational stress. We wanted to use short, subjective and user-friendly tools for the assessment of QoL, work ability and sleep quality. These 
instruments could easily be used for screening, also in occupational and primary healthcare.

\section{PARTICIPANTS AND METHODS \\ Participants}

This cross-sectional study was part of the PORTAAT (PORi To Aid Against Threats) study conducted among employees of the city of Pori (83497 inhabitants in 2014) in South-Western Finland in 2014 and 2015. The participating work units were selected by the chief of the Welfare Unit of Pori. Invitations to participate and information of the study were sent to employees via email by the managers of the selected ten work units (total number of employees 2570). The employees willing to participate contacted the study contact person at their work unit, who then sent their contact information to the study nurse. There were no exclusion criteria. A total of 836 employees (104 males, 732 females) participated in the study in 2014. The response rate in 2014 was $32.5 \%$. Complete information about data collection from that year has been described earlier. ${ }^{17}$ All the initial respondents were invited to the second part of the study in 2015, and 710 of them (79 males, 631 females) attended. In the present work, all the information is from the year 2015, and this data was chosen because complete information about psychosocial risk factors was available only from that year. The gender distribution of the study participants corresponds to the standard gender distribution of the employees of Pori. The participants' occupations included librarians, museum employees, janitors, IT workers, social workers, nurses, physicians, administrative officials and general office staff. The involved employment sectors reported according to the number of employees participating in the study in 2015 were health and welfare (275 employees), social work (198), technical services (143), education and culture (62) and administration (32).

\section{Quality of life}

QoL was assessed with the EUROHIS-QOL 8-item index. ${ }^{18}$ This is a shortened version of the World Health Organization Quality of Life Assessment scale (WHOQOLBREF), a widely used instrument for the assessment of generic QoL. ${ }^{719}$ The domains in both questionnaires are the general, physical, psychological, social and environmental aspects of QoL. The EUROHIS-QOL instrument has been validated in several European countries. ${ }^{1}$ The participants of the present study answered the questions at home before the study visits. Every question was scored from 1 to 5 ( 1 for very poor and 5 for very good). All scores were then added together and divided by 8 (the sum of the questions) to obtain the EUROHIS-QOL mean score. ${ }^{1}$

\section{Work-related measures}

Work ability was assessed with the question 'What is your current work ability compared with your lifetime best?'. This is the first item of the widely used Work Ability Index
(WAI), ${ }^{9}$ referred to as the Work Ability Score (WAS). It has a $0-10$ response scale, where 0 stands for 'completely unable to work' and 10 stands for 'work ability at its best'. Work ability was considered poor for scores of $0-5$, moderate for scores of 6-7, good for scores of 8-9 and excellent for a score of 10 points, based on the same values that have been used in the WAI. ${ }^{20}$ Work-related stress was evaluated with Bergen Burnout Indicator 15 (BBI-15). ${ }^{13}$ The BBI-15 measures three dimensions of burnout: exhaustion, cynicism and reduced professional efficacy. Responses are rated on a 6-point Likert-type scale ( $1=$ totally disagree, $6=$ totally agree). In this work, we used the total score from all three dimensions, which can vary from 15 to 90, with higher scores indicating more severe burnout symptoms. Burnout symptoms are in this indicator classified as severe, moderate, mild and no burnout, with specific threshold values according to gender and age. ${ }^{13}$ We assessed burnout as a binary variable where all scores from mild to severe burnout were set to indicate the presence of burnout symptoms.

\section{Sleep-related measures}

Self-reported sleep quality was assessed with the question 'During the past month, how would you rate your sleep quality overall?' (very good, good, poor or very poor). In the analyses, the two lowest classes of sleep quality were combined and set to indicate poor sleep quality. Sleep duration was assessed with the question 'During the past month, how many hours of sleep did you normally get at night?'. The participants were asked to answer the question in a free field, and sleep duration was handled as a continuous variable in the analyses. Both of these questions are items from the well-validated Pittsburgh Sleep Quality Index (PSQI) ${ }^{10}$ which has good internal consistency $(\alpha=0.83)$ and testretest reliability $(\mathrm{r}=0.82$; over an average of 19 days $) .^{21}{ }^{22}$

\section{Psychological symptoms}

Depressive symptoms were assessed with the Major Depression Inventory (MDI) questionnaire. ${ }^{23}$ This inventory can be used as a diagnostic tool for major depression (according to DSM IV diagnostic criteria) as well as an assessment tool for the severity of depressive symptoms. ${ }^{1123}$ To assess severity of depressive symptoms, a total score of $0-20$ is considered as no symptoms, $21-25$ as mild symptoms, $26-30$ as moderate symptoms and $31-50$ as severe depressive symptoms. In this work, the diagnostic tool was used to determine whether a person had depression or not. Anxiety was assessed with the General Anxiety Disorder 7-item Scale (GAD-7). ${ }^{12}$ In the GAD-7, a total score of $0-4$ is considered as no anxiety, 5-9 as mild anxiety, 10-14 as moderate anxiety and $15-21$ as severe anxiety. A total score of 10 was used as a cut-off point when a binary variable for anxiety was used in our analyses. This cut-off is recommended by the developers of the GAD-7 questionnaire. ${ }^{12}$ The participants with severe 
depressive or anxious symptoms were referred to the occupational healthcare for further follow-up.

\section{Other measures}

Smoking status was assessed by a questionnaire. Nonsmoking was defined as having never smoked or having quit smoking $>12$ months ago. Height and weight were measured by a study nurse with subjects in the standing position without shoes and outer garments. Weight was measured to the nearest $0.1 \mathrm{~kg}$ with calibrated scales and height to the nearest $0.5 \mathrm{~cm}$ with a wall-mounted stadiometer. Body mass index (BMI) was calculated as weight $(\mathrm{kg})$ divided by the square of height $\left(\mathrm{m}^{2}\right)$. Information concerning diseases diagnosed by a physician, medication used regularly, marital status (cohabiting or not), working times (3-shift work or not) and education level (vocational school, college-level education or university-level education) was gathered using self-administered questionnaires and medical records. Alcohol consumption was assessed using the 3-item Alcohol Use Disorders Identification Test (AUDIT-C) ${ }^{24}$ with a cut-off of 5 points for harmful alcohol use in women and 6 points in men. ${ }^{25}{ }^{26}$ Disease burden was defined as having at least one chronic disease diagnosed by a physician.

\section{Statistical analysis}

Continuous variables are presented with means and SD together with $95 \%$ CI. Categorical variables are summarised with counts and percentages (\%). Association between sleep quality and background variables was evaluated using a chi-square test or a one-way analysis of variance (ANOVA).

Association between QoL/work ability and background variables including sleep quality were examined first one by one (univariate approach), with one-way ANOVA or with linear regression. A multivariable model was then built up, and age, gender and all factors with a significant association with QoL and/or work ability in the univariate approach were entered into the model. The method used was a linear model and assumptions were checked using studentised residuals.

All statistical tests were performed as two-sided, with a significance level set at 0.05 . The analyses were performed using an SAS System V.9.4 for Windows (SAS Institute, Cary, North Carolina, USA).

\section{Patient and public involvement}

Information events about the PORTAAT study with guidance for the management of physical and psychosocial well-being were arranged for the employees of the selected work units. All participants were given personalised lifestyle counselling at the study visits. The chief of the Welfare Unit of Pori has been informed regularly about the published study results. The participants of this study were not involved in the design or development of the study.

\section{RESULTS}

The study cohort consisted of 710 employees with a mean age of 49 years (SD 10, range 20-68), 89\% of whom were female.

\section{Characteristics of the participants}

Table 1 displays the basic characteristics of all the participants, also classified according to their sleep quality. Sleep quality was reported very good by $14.5 \%$, good by $62.1 \%$, poor by $21.2 \%$ and very poor by $2.1 \%$ of the participants. Poor and very poor sleep quality were combined and set to indicate poor sleep quality in the analyses. Self-reported sleep quality was negatively associated with disease burden, the prevalence of depression and severity of depressive symptoms, anxiety and work stress, and positively associated with QoL and work ability. Better sleep quality was associated with longer sleep duration $(\mathrm{p}<0.0001)$. There were only five participants with a previously diagnosed obstructive sleep apnoea and three with restless legs syndrome. During the past month, $14.8 \%$ of the participants had used sleep medication at least occasionally. The use of sleep medication was more common in women $(15.1 \%$ in women vs $12.6 \%$ in men, $\mathrm{p}=0.038)$.

Only $9(1.3 \%)$ of the participants were diagnosed as depressive according to the MDI diagnostic tool. All of them were also classified as anxious (GAD-7 score $>10$ ). The measures from these two psychological symptoms were combined for multivariable analyses.

\section{Quality of life}

As seen in table 2, the EUROHIS-QOL mean score among all participants was 4.07 (SD 0.51) with no significant difference between genders $(\mathrm{p}=0.94)$. In the univariate approach, QoL was positively associated with good sleep quality, university-level education, cohabiting, lower BMI and younger age, and negatively associated with occupational stress, depression, anxiety and disease burden.

In the multiway analysis of covariance, QoL was positively associated with good sleep quality, cohabiting, university-level education and lower BMI, and negatively associated with occupational stress, depression and/or anxiety and disease burden (table 2).

\section{Work ability}

Work ability was reported excellent by $15.2 \%$, good by $64.9 \%$, moderate by $16.1 \%$ and poor by $3.8 \%$ of the participants. The WAS mean score among all participants was 8.31 (SD 1.37), and the median was 9.0 (Q1:8.0, Q3:9.0). In the univariate approach, work ability was positively associated with good sleep quality, younger age, lower BMI, university-level education, female gender and 3-shift work, and negatively associated with disease burden, depression, anxiety and occupational stress.

In the multiway analysis of covariance, work ability was positively associated with good sleep quality, younger age, lower BMI and university-level education, and negatively associated with occupational stress and disease burden (table 3). 
Table 1 Characteristics of all the participants and classified according to self-reported sleep quality

\begin{tabular}{|c|c|c|c|c|c|}
\hline & \multirow[b]{2}{*}{ All participants } & \multicolumn{3}{|l|}{ Sleep quality } & \multirow[b]{2}{*}{$P$ value } \\
\hline & & Very good (n=103) & Good $(n=441)$ & Poor $(n=166)$ & \\
\hline Age mean, years (SD) & $49.0(9.7)$ & $47.5(10.6)$ & $49.1(9.7)$ & $49.8(9.2)$ & 0.072 \\
\hline Gender, n (\%) & & & & & 0.10 \\
\hline Female & $631(88.9)$ & $85(13.5)$ & $397(62.9)$ & $149(23.6)$ & \\
\hline Male & $79(11.1)$ & $18(22.8)$ & $44(55.7)$ & $17(21.5)$ & \\
\hline Education, n (\%) & & & & & 0.36 \\
\hline Vocational school & $21(3)$ & $4(19.1)$ & $14(66.7)$ & $3(14.3)$ & \\
\hline College-level & $361(51.6)$ & $53(14.7)$ & $232(64.3)$ & $76(21.1)$ & \\
\hline University-level & $318(45.4)$ & $45(14.2)$ & $188(59.1)$ & $85(26.7)$ & \\
\hline Cohabiting, n (\%) & & & & & 0.64 \\
\hline Yes & $575(81.2)$ & $83(14.4)$ & $353(61.4)$ & $139(24.2)$ & \\
\hline No & $133(18.8)$ & $20(15.0)$ & $86(64.7)$ & $27(20.3)$ & \\
\hline 3-shift work, n (\%) & & & & & 0.41 \\
\hline Yes & 76 (10.9) & $15(19.7)$ & $44(57.9)$ & 17 22.4) & \\
\hline No & $620(89.1)$ & $87(14.0)$ & $386(62.3)$ & $147(23.7)$ & \\
\hline Smoking, n (\%) & & & & & 0.45 \\
\hline Yes & $64(9.0)$ & $9(14.1)$ & $44(68.8)$ & $11(17.2)$ & \\
\hline No & $645(91.0)$ & $94(14.6)$ & $396(61.4)$ & $155(24.0)$ & \\
\hline Harmful alcohol consumption, n (\%) & & & & & 0.55 \\
\hline Yes & $101(14.2)$ & $18(17.8)$ & $59(58.4)$ & $24(23.8)$ & \\
\hline No & $609(85.8)$ & $85(14.0)$ & $382(62.7)$ & $142(23.3)$ & \\
\hline Body mass index mean $(95 \% \mathrm{Cl})$ & 26.8 (26.42 to 27.13 ) & 26.4 (25.50 to 27.25$)$ & 27.0 (26.54 to 27.46$)$ & 26.5 (25.72 to 27.24$)$ & 0.92 \\
\hline Disease burden*, n (\%) & & & & & 0.0016 \\
\hline Yes & $468(65.9)$ & $55(11.8)$ & $289(61.8)$ & $124(26.5)$ & \\
\hline No & $242(34.1)$ & $48(19.8)$ & $152(62.8)$ & $42(17.4)$ & \\
\hline Depression (MDI), n (\%) & & & & & 0.016 \\
\hline Yes & $9(1.3)$ & $0(0.0)$ & $3(33.3)$ & $6(66.7)$ & \\
\hline No & $701(98.7)$ & $103(14.7)$ & $438(62.5)$ & $160(22.8)$ & \\
\hline MDI mean score $(95 \% \mathrm{Cl})$ & $5.0(4.57$ to 5.43$)$ & $2.4(1.75$ to 2.97$)$ & 4.1 (3.59 to 4.51$)$ & 9.2 (8.09 to 10.27$)$ & $<0.0001$ \\
\hline Level of anxiety (GAD-7), n (\%) & & & & & $<0.0001$ \\
\hline No anxiety & $534(75.2)$ & $92(17.2)$ & $343(64.2)$ & 99 (18.5) & \\
\hline Mild anxiety & $143(20.1)$ & $10(7.0)$ & $85(59.4)$ & $48(33.6)$ & \\
\hline Moderate anxiety & $26(3.7)$ & $1(3.9)$ & $10(38.5)$ & $15(57.7)$ & \\
\hline Severe anxiety & $7(1.0)$ & $0(0.0)$ & $3(42.9)$ & $4(57.1)$ & \\
\hline BBI15 mean total score $(95 \% \mathrm{Cl})$ & 31.6 (30.82 to 32.41$)$ & 28.3 (26.43 to 30.23$)$ & 31.0 (30.05 to 31.99$)$ & 35.4 (33.60 to 37.20$)$ & $<0.0001$ \\
\hline Occupational stress (BBI15), n (\%) & & & & & $<0.0001$ \\
\hline No stress & $592(89.4)$ & $97(16.4)$ & $374(63.2)$ & $121(20.4)$ & \\
\hline Stress & $70(10.6)$ & $3(4.3)$ & $38(54.3)$ & $29(41.4)$ & \\
\hline Sleep duration mean $(95 \% \mathrm{Cl})$ & $7.00(6.93$ to 7.07$)$ & 7.50 (7.35 to 7.66$)$ & 7.17 (7.09 to 7.24$)$ & $6.23(6.09$ to to 6.38$)$ & $<0.0001$ \\
\hline EUROHIS mean score $(95 \% \mathrm{Cl})$ & 4.07 (4.03 to 4.11$)$ & 4.38 (4.30 to 4.45$)$ & 4.09 (4.05 to 4.14$)$ & 3.83 (3.75 to 3.91$)$ & $<0.0001$ \\
\hline WAS mean score $(95 \% \mathrm{Cl})$ & 8.31 (8.21 to 8.41$)$ & 8.99 (8.78 to 9.20$)$ & 8.34 (8.22 to 8.46$)$ & 7.80 (7.55 to 8.04$)$ & $<0.0001$ \\
\hline Level of work ability (WAS), $n$ (\%) & & & & & $<0.0001$ \\
\hline Poor & $27(3.8)$ & $1(3.7)$ & $12(44.4)$ & 14 (51.9) & \\
\hline Moderate & $114(16.1)$ & $3(2.6)$ & $69(60.5)$ & $42(36.8)$ & \\
\hline Good & 459 (64.9) & 61 (13.3) & 298 (64.9) & $100(21.8)$ & \\
\hline Excellent & 107 (15.2) & 37 (34.6) & $60(56.1)$ & $10(9.4)$ & \\
\hline
\end{tabular}

${ }^{*}$ At least one chronic disease diagnosed by a physician.

BBI15, Bergen Burnout Indicator 15; EUROHIS, EUROHIS QOL 8-item index; GAD-7, General Anxiety Disorder 7-item Scale; MDI, Major Depression Inventory; WAS, Work Ability Score.

\section{DISCUSSION}

In this study, we managed to show that occupational stress, self-reported sleep quality and disease burden were strongly associated with both QoL and work ability in public sector employees. In addition, QoL was tightly associated with BMI and depression and/or anxiety. To 
Table 2 Factors associated with quality of life in a univariate approach and in a multivariable model. EUROHIS means/slope together with $95 \% \mathrm{Cl}$ are based on model estimates

\begin{tabular}{|c|c|c|c|c|c|c|c|c|}
\hline & \multicolumn{3}{|l|}{ Univariate } & \multicolumn{5}{|l|}{ Multivariable } \\
\hline & $\begin{array}{l}\text { EUROHIS total } \\
\text { mean/slope }\end{array}$ & $95 \% \mathrm{Cl}$ & $P$ value & $\begin{array}{l}\text { EUROHIS total } \\
\text { model based mean/ } \\
\text { slope }\end{array}$ & $95 \% \mathrm{Cl}$ & F value & df & $P$ value \\
\hline Gender & & & 0.94 & & & 0.00 & 1 & 0.99 \\
\hline Female & 4.07 & 4.03 to 4.11 & & 3.54 & 3.38 to 3.69 & & & \\
\hline Vocational school & 3.83 & 3.61 to 4.05 & & 3.37 & 3.11 to 3.62 & & & \\
\hline College-level & 4.05 & 4.00 to 4.11 & & 3.59 & 3.44 to 3.74 & & & \\
\hline University-level & 4.11 & 4.05 to 4.16 & & 3.66 & 3.51 to 3.81 & & & \\
\hline Cohabiting & & & 0.011 & & & 5.72 & 1 & 0.017 \\
\hline Yes & 4.09 & 4.05 to 4.13 & & 3.59 & 3.43 to 3.75 & & & \\
\hline No & 4.08 & 4.04 to 4.12 & & & & & & \\
\hline Harmful alcohol consumption & & & 0.33 & & & & & \\
\hline Yes & 4.12 & 4.02 to 4.22 & & & & & & \\
\hline No & 4.06 & 4.02 to 4.11 & & & & & & \\
\hline Body mass index & -0.020 & -0.028 to -0.012 & $<0.0001$ & -0.018 & -0.025 to -0.011 & 23.91 & 1 & $<0.0001$ \\
\hline Disease burden* & & & $<0.0001$ & & & 13.35 & 1 & 0.0003 \\
\hline Yes & 3.99 & 3.95 to 4.04 & & 3.47 & 3.31 to 3.63 & & & \\
\hline No & 4.22 & 4.16 to 4.29 & & 3.61 & 3.44 to 3.77 & & & \\
\hline Depression† & & & $<0.0001$ & & & & & \\
\hline Depression and/or anxiety†§ & & & & & & 13.92 & 2 & $<0.0001$ \\
\hline No depression/ No anxiety & & & & 3.89 & 3.77 to 4.00 & & & \\
\hline Only anxiety & & & & 3.59 & 3.36 to 3.82 & & & \\
\hline Depression and anxiety & & & & 3.14 & 2.81 to 3.46 & & & \\
\hline Occupational stress & & & $<0.0001$ & & & 39.30 & 1 & $<0.0001$ \\
\hline Yes & 3.63 & 3.51 to 3.74 & & 3.35 & 3.18 to 3.53 & & & \\
\hline No & 4.13 & 4.09 to 4.17 & & 3.72 & 3.56 to 3.88 & & & \\
\hline 3-shift work & & & 0.089 & & & 0.55 & 1 & 0.46 \\
\hline Yes & 4.16 & 4.02 to 4.10 & & 3.56 & 3.37 to 3.74 & & & \\
\hline No & 4.06 & 4.05 to 4.28 & & 3.52 & 3.36 to 3.67 & & & \\
\hline Self-reported sleep quality & & & $<0.0001$ & & & 22.02 & 2 & $<0.0001$ \\
\hline Very good & 4.38 & 4.30 to 4.45 & & 3.74 & 3.56 to 3.92 & & & \\
\hline Good & 4.09 & 4.05 to 4.14 & & 3.53 & 3.36 to 3.69 & & & \\
\hline Poor & 3.83 & 3.75 to 3.91 & & 3.34 & 3.18 to 3.51 & & & \\
\hline
\end{tabular}

*At least one chronic disease diagnosed by a physician.

†Defined by Major Depression Inventory diagnostic tool (DSM IV).

‡General Anxiety Disorder 7-item Scale.

§General Anxiety Disorder 7-item Scale, moderate or severe anxiety.

IBergen Burnout Indicator 15, at least mild occupational stress.

$\mathrm{df}$, degrees of freedom; EUROHIS, EUROHIS QOL 8-item index. 
Table 3 Factors associated with work ability in a univariate approach and in a multivariable model. was means/slope together with $95 \% \mathrm{Cl}$ are based on model estimates

\begin{tabular}{|c|c|c|c|c|c|c|c|c|}
\hline & \multicolumn{3}{|l|}{ Univariate } & \multicolumn{5}{|l|}{ Multivariable } \\
\hline & WAS estimate/slope & $95 \% \mathrm{Cl}$ & $P$ value & $\begin{array}{l}\text { WAS model based } \\
\text { estimate/slope }\end{array}$ & $95 \% \mathrm{Cl}$ & F value & df & $P$ value \\
\hline Age & -0.019 & -0.029 to -0.0090 & 0.0002 & -0.012 & -0.022 to -0.0018 & 5.34 & 1 & 0.021 \\
\hline Gender & & & 0.027 & & & 3.36 & 1 & 0.067 \\
\hline Female & 8.35 & 8.24 to 8.46 & & 7.83 & 7.43 to 8.23 & & & \\
\hline Male & 7.99 & 7.68 to 8.29 & & 7.56 & 7.09 to 8.04 & & & \\
\hline Education & & & 0.0079 & & & 4.74 & 2 & 0.0091 \\
\hline Vocational school & 7.90 & 7.30 to 8.50 & & 7.42 & 6.76 to 8.07 & & & \\
\hline College-level & 8.18 & 8.04 to 8.32 & & 7.70 & 7.32 to 8.09 & & & \\
\hline University-level & 8.48 & 8.33 to 8.63 & & 7.98 & 7.58 to 8.37 & & & \\
\hline Cohabiting & & & 0.91 & & & 0.04 & 1 & 0.85 \\
\hline Yes & 8.31 & 8.20 to 8.42 & & 7.69 & 7.27 to 8.10 & & & \\
\hline No & 8.30 & 8.06 to 8.53 & & 7.71 & 7.26 to 8.18 & & & \\
\hline Smoking & & & 0.19 & & & & & \\
\hline Yes & 8.10 & 7.76 to 8.44 & & & & & & \\
\hline No & 8.33 & 8.23 to 8.44 & & & & & & \\
\hline Harmful alcohol consumption & & & 0.35 & & & & & \\
\hline Yes & 8.43 & 8.16 to 8.70 & & & & & & \\
\hline No & 8.30 & 8.18 to 8.40 & & & & & & \\
\hline Body mass index & -0.036 & -0.057 to -0.016 & 0.0006 & -0.023 & -0.042 to -0.0041 & 5.71 & 1 & 0.017 \\
\hline Disease burden* & & & $<0.0001$ & & & 12.23 & 1 & 0.0005 \\
\hline Yes & 8.07 & 7.95 to 8.20 & & 7.52 & 7.11 to 7.95 & & & \\
\hline No & 8.77 & 8.60 to 8.93 & & 7.87 & 7.44 to 8.30 & & & \\
\hline Depression† & & & 0.0083 & & & & & \\
\hline Yes & 7.11 & 6.22 to 8.01 & & & & & & \\
\hline No & 8.33 & 8.23 to 8.43 & & & & & & \\
\hline Level of anxiety $\ddagger$ & & & $<0.0001$ & & & & & \\
\hline No & 8.55 & 8.44 to 8.66 & & & & & & \\
\hline Mild & 7.59 & 7.38 to 7.81 & & & & & & \\
\hline Moderate & 7.44 & 6.95 to 7.94 & & & & & & \\
\hline Severe & 8.00 & 7.03 to 8.97 & & & & & & \\
\hline Depression and/or anxiety†§ & & & & & & 1.73 & 2 & 0.17 \\
\hline No depression / No anxiety & & & & 8.02 & 7.72 to 8.31 & & & \\
\hline Only anxiety & & & & 7.67 & 7.07 to 8.27 & & & \\
\hline Depression and anxiety & & & & 7.41 & 6.57 to 8.25 & & & \\
\hline Occupational stress & & & $<0.0001$ & & & 29.80 & 1 & $<0.0001$ \\
\hline Yes & 7.47 & 7.18 to 7.76 & & 7.28 & 6.82 to 7.74 & & & \\
\hline No & 8.47 & 8.37 to 8.57 & & 8.12 & 7.70 to 8.54 & & & \\
\hline 3-shift work & & & 0.0040 & & & 3.75 & 1 & 0.053 \\
\hline Yes & 8.74 & 8.43 to 9.05 & & 7.84 & 7.36 to 8.33 & & & \\
\hline No & 8.26 & 8.15 to 8.36 & & 7.55 & 7.16 to 7.95 & & & \\
\hline Self-reported sleep quality & & & $<0.0001$ & & & 14.44 & 2 & $<0.0001$ \\
\hline Very good & 9.00 & 8.73 to 9.25 & & 8.13 & 7.66 to 8.60 & & & \\
\hline Good & 8.34 & 8.22 to 8.47 & & 7.68 & 7.25 to 8.10 & & & \\
\hline Poor & 7.80 & 7.59 to 8.00 & & 7.29 & 6.86 to 7.72 & & & \\
\hline
\end{tabular}

${ }^{\star}$ At least one chronic disease diagnosed by a physician

†Defined by Major Depression Inventory diagnostic tool (DSM IV)

‡General Anxiety Disorder 7-item Scale.

$\S$ General Anxiety Disorder 7-item Scale, moderate or severe anxiety.

IBergen Burnout Indicator 15, at least mild occupational stress.

$\mathrm{df}$, degrees of freedom; WAS, Work Ability Score. 
our knowledge, few studies have evaluated QoL and work ability simultaneously among apparently healthy, working-age individuals, with information about a wide range of factors potentially influencing these two variables.

Occupational stress was the factor most strongly associated with both QoL and work ability in this study. It is well known, that job strain is an important factor affecting employees' health and well-being. ${ }^{327} 28$ Occupational stress is known to be associated, for example, with poor sleep quality ${ }^{29}$ lower work ability ${ }^{4}$ and mental health problems. ${ }^{30}$ Furthermore, work stress was found to be associated with elevated mortality rates in patients with cardiometabolic disease in a large multicohort study. ${ }^{31}$ Work stress has also been found to have a negative association with QoL in several studies. ${ }^{3}{ }^{27}$ The interesting finding in our study was that the association of occupational stress with QoL and WAS was strong, regardless of the fact that our study population had low rates of occupational stress. Only $10.6 \%$ of the participants in our study had at least mild occupational stress symptoms, and severe symptoms were very rare. It is thus possible that even low levels of occupational stress can have an important influence on a person's work ability and QoL. These results highlight the need for screening and handling of work stress among municipal employees.

Self-reported sleep quality was tightly associated with both QoL and work ability in this study. A negative association between poor sleep quality and QoL has previously been demonstrated among patients with sleep disorders and other medical conditions, ${ }^{32-35}$ and studies on shift workers have shown a clear association between sleep quality and QoL. ${ }^{36}$ Furthermore, in a previous work on higher education students, Marques $e t$ al showed that self-reported sleep quality remained a significant predictor of most aspects of QoL, regardless of the presence of psychopathological symptoms, such as depression. ${ }^{5}$ Sleep problems have in previous literature also been linked to poorer work ability and an increased rate of sickness absence. ${ }^{38}{ }^{39} \mathrm{In}$ addition, $\mathrm{Ng}$ and Chan have shown a positive association between good sleep quality and work ability among Hong Kong construction workers. ${ }^{6}$ However, in this study, we managed to show that self-reported sleep quality is significantly associated with both QoL and work ability among apparently healthy employees not restricted to a specific occupation and working mainly in regular morning shifts. The associations remained significant also in the multivariable models, where many potential confounding factors could be taken into account.

Disease burden, higher BMI and lower educational level were negatively associated with both QoL and work ability in this study, as well as in previous literature. Chronic diseases are known to have a negative association with $\mathrm{QoL}^{1}$ and with work ability. ${ }^{240}$ Lower BMI has been linked to better QoL $^{41}$ and to better work ability, ${ }^{43}$ and higher education has been positively associated with $\mathrm{QoL}^{44}$ and with work ability. ${ }^{45} \mathrm{In}$ our study, as well as in previous literature, older age was associated with poorer work ability, ${ }^{46}$ but no significant association was found between age and QoL. This finding is consistent with the Finnish reference values for the EUROHIS-QOL 8-item index. ${ }^{47}$ Furthermore, cohabiting had a significant positive association with QoL in our study, as has previously been observed in a population-based study in Sweden. ${ }^{48}$ Cohabiting has previously been linked to better health and work ability, for example, in an unemployed population, ${ }^{49}$ but in our setting, where only active work force was studied, there was no significant association between cohabiting and work ability.

An interesting finding in our study was that depression and/or anxiety was strongly associated with QoL but did not have a significant association with work ability in the multivariable model. Depression and anxiety are known to have a negative impact on QoL ${ }^{50-52}$ but depression also affects a person's ability to work. ${ }^{253}$ However, depression often leads to sickness absence, which means that these people are not in the active work force. In our study population, depression and anxiety were relatively rare conditions, and most of the cases were mild. Only $9(1.3 \%)$ of the participants met the diagnostic criteria for major depression and $33(4.6 \%)$ of the participants where categorised as moderately or severely anxious. It is known that not all depressive patients consider themselves unable to work. ${ }^{53}$ These patients may benefit from the schedule and routine of work life and do not want to seek sick leave, while depression still affects their QoL. In the Finnish Current Care Guidelines for depression, sick leave is not recommended in mild depression and the need for sick leave in moderate depression should be evaluated individually. ${ }^{54}$ According to these recommendations, those depressive patients whose work ability is not affected should remain in the active work force. Furthermore, as the prevalence of depression and anxiety in our study population was low, the generalisability of these results can be questioned.

In this study, 3-shift work was not significantly associated either with QoL or with work ability in the multivariable models. In the univariate approach, the work ability of the 3-shift workers was better $(\mathrm{p}=0.0040)$, but no significant difference was seen in QoL. Somewhat surprisingly, 3-shift work did not seem to have any adverse effects on the participants' well-being in our study. There was no difference in sleep quality or occupational stress compared with the regular morning shift workers. Almost all 3-shift workers in our study were women working as nurses or social workers. Their mean age was 45.6 years, which is 3.5 years younger than the mean age of the whole study population. In addition to the younger age, one possible explanation for their well-being is that they may have voluntarily chosen to work in shifts and feel that it is a suitable way of working for them. Those shift workers who have had health problems or difficulties with sleep due to shift work may have changed to day work. ${ }^{55}$ Another unexpected result in this work was that harmful alcohol consumption did not have adverse effects on sleep quality, QoL or work ability. However, even though there were 101 (14.2\%) participants that fulfilled the definition of 'harmful drinking' in the AUDIT-C, heavy drinking was very rare in this predominantly female, active work force population. We assume that these people may consume alcohol mainly during weekends, which diminishes the effects on everyday life and work.

We acknowledge some limitations of the study. We cannot determine the causality of the found associations because 
of the cross-sectional nature of the study. A possible healthy worker effect ${ }^{56}$ can be present because only subjects in the active work force were studied. In addition, the initial response rate in the first part of the study in 2014 was only $32.5 \%$ (and $84.9 \%$ of them attended the study in 2015). It is known that response rates in email surveys tend to be lower than in mail surveys,${ }^{57}$ but it can nevertheless cause selection bias. It is possible that the healthiest part of the work force is also the most willing to attend voluntary health surveys, which may result in the possibility that our results reflect the situation in the mainly healthy section of the work force. However, the mean annual rate of sickness absence days did not vary significantly between the study participants and the non-participants on the included employment sectors. According to the records obtained from the city of Pori, the mean incidence of sickness absence days was 11 days per year among the study participants during the 2-year time period (2014-2015). ${ }^{58}$ The mean sickness absence rate among all employees of the selected work units was 12 days according to the personnel report of the city of Pori in $2015 .{ }^{59}$ The gender distribution in our study ( $89 \%$ females) resembles the distribution among employees of the city of Pori and is close to the gender distribution of the large Finnish prospective study on the public sector employees. ${ }^{60}$ The information about alcohol consumption was collected by self-assessment, which may be influenced by social desirability. In addition, we, unfortunately, do not have data of possible menopausal symptoms, which may have affected our results in women.

The strengths of our study are that we could take into account several aspects associated with the employees' QoL and work ability. All questionnaires were completed by the participants at home before the examination was performed. In this study, the approaches to sleep quality, QoL and work ability were all subjective, which emphasises the importance of personal experience in evaluating these factors. We assessed self-reported sleep quality and work ability with single questions. This approach was chosen over longer questionnaires because a single question could also be used at a normal physician's appointment in primary or occupational healthcare for the evaluation of these factors. The self-reported sleep quality question we used was from the PSQI, and it has previously been shown to be closely related with QoL. ${ }^{5}$ With this question, we showed a clear association of sleep quality with QoL and with work ability. However, it would be interesting to further assess this connection in a similar population with a more detailed questionnaire to determine whether the different components of sleep have different impacts on QoL and work ability. The WAS score we used for the evaluation of work ability has been shown to have a strong association with the WAI and is reliable in evaluating work ability. ${ }^{61}$ WAS has also been shown to predict disability pension and long-term sickness absence according to a Finnish register-based study. ${ }^{62}$ The associations of selfreported sleep quality with both QoL and with work ability were clear and in line with previous literature even when studied with these simple tools.

\section{CONCLUSIONS}

In this paper, we showed that occupational stress and selfreported sleep quality are strongly associated with both QoL and work ability among Finnish public sector employees. According to our results, even a low level of occupational stress has a significant negative association with QoL and work ability. These findings highlight the need for screening and handling work stress and sleep problems in occupational and primary healthcare. We suggest that short, self-reported assessment tools could be used for this purpose.

Contributors EB, EL, SM, PR and PEK contributed to the conception or design of the work, and to the acquisition, analysis or interpretation of data for the work. EB and PEK drafted the manuscript. All authors critically revised the manuscript, gave final approval, and agreed to be accountable for all aspects of work, ensuring integrity and accuracy.

Funding This study was supported by the Hospital District of Satakunta, the Hospital District of Southwest Finland and Etera Mutual Pension Insurance Company.

\section{Competing interests None declared.}

Patient and public involvement Patients and/or the public were involved in the design, or conduct, or reporting, or dissemination plans of this research. Refer to the 'Participants and Methods' section for further details.

\section{Patient consent for publication Not required.}

Ethics approval All procedures performed in studies involving human participants were in accordance with the ethical standards of the institutional and/or national research committee and with the 1964 Helsinki Declaration and its later amendments or comparable ethical standards. The study protocol and consent forms were reviewed and approved by the Ethics Committee of the Hospital District of Southwest Finland (ETMK 43/180/2013).

Provenance and peer review Not commissioned; externally peer reviewed.

Data availability statement Data are available upon reasonable request. The datasets used and/or analysed during the current study are available from the corresponding author on request.

Open access This is an open access article distributed in accordance with the Creative Commons Attribution Non Commercial (CC BY-NC 4.0) license, which permits others to distribute, remix, adapt, build upon this work non-commercially, and license their derivative works on different terms, provided the original work is properly cited, appropriate credit is given, any changes made indicated, and the use is non-commercial. See: http://creativecommons.org/licenses/by-nc/4.0/.

\section{ORCID iD}

Elina Bergman http://orcid.org/0000-0002-7694-3799

\section{REFERENCES}

1 Schmidt S, Mühlan H, Power M. The EUROHIS-QOL 8-item index: psychometric results of a cross-cultural field study. Eur J Public Health 2006;16:420-8.

2 Shiri R, Kaila-Kangas L, Ahola K, et al. The relation of co-occurring musculoskeletal pain and depressive symptoms with work ability. $J$ Occup Environ Med 2013;55:1281-5.

3 Sarafis P, Rousaki E, Tsounis A, et al. The impact of occupational stress on nurses' caring behaviors and their health related quality of life. BMC Nurs 2016;15:1-9.

4 Yong M, Nasterlack M, Pluto R-P, et al. Occupational stress perception and its potential impact on work ability. Work 2013;46:347-54.

5 Marques DR, Meia-Via AMS, da Silva CF, et al. Associations between sleep quality and domains of quality of life in a non-clinical sample: results from higher education students. Sleep Health 2017;3:348-56.

$6 \mathrm{Ng}$ JYK, Chan AHS. The work ability of Hong Kong construction workers in relation to individual and work-related factors. Int $J$ Environ Res Public Health 2018;15:1-3.

7 THE WHOQOL GROUP. Development of the world Health organization WHOQOL-BREF quality of life assessment. The WHOQOL group. Psychol Med 1998;28:551-8. 
8 Idler EL, Benyamini Y. Self-Rated health and mortality: a review of twenty-seven community studies. J Health Soc Behav 1997;38:21-37 http://www.ncbi.nlm.nih.gov/pubmed/9097506

9 Ilmarinen J. The work ability index (WAI). Occup Med 2006;57:160.

10 Buysse DJ, Reynolds CF, Monk TH, et al. The Pittsburgh sleep quality index: a new instrument for psychiatric practice and research. Psychiatry Res 1989;28:193-213.

11 Bech P, Timmerby N, Martiny K, et al. Psychometric evaluation of the major depression inventory (MDI) as depression severity scale using the lead (longitudinal expert assessment of all data) as index of validity. BMC Psychiatry 2015;15:1-7.

12 Spitzer RL, Kroenke K, Williams JBW, et al. A brief measure for assessing generalized anxiety disorder. Arch Intern Med 2006;166:1092-7.

13 Näätänen P, Aro A, Mathiesen SB, et al. Bergen Burnout Indicator 15. Helsinki: Edita, 2003.

14 Bergman E, Löyttyniemi E, Rautava P, et al. Ideal cardiovascular health and quality of life among Finnish municipal employees. Prev Med Rep 2019;15:100922.

15 Chiu M-C, Wang M-JJ, Lu C-W, et al. Evaluating work ability and quality of life for clinical nurses in Taiwan. Nurs Outlook 2007;55:318-26.

16 Sörensen LE, Pekkonen MM, Männikkö KH, et al. Associations between work ability, health-related quality of life, physical activity and fitness among middle-aged men. Appl Ergon 2008;39:786-91.

17 Veromaa V, Kautiainen $\mathrm{H}$, Saxen U, et al. Ideal cardiovascular health and psychosocial risk factors among Finnish female municipal workers. Scand J Public Health 2017;45:50-6.

18 Power M. Development of a common instrument for quality of life. EUROHIS Dev Common Instruments Heal Surv 2003;57:145-59 http://www.euro.who.int/en/publications/abstracts/eurohisdeveloping-common-instruments-for-health-surveys

19 WHOQOL Group. The world Health organization quality of life assessment (WHOQOL): development and general psychometric properties. Soc Sci Med 1998;46:1569-85.

20 Gould R, Ilmarinen J, Jarvisalo J. Dimensions of work ability. Helsinki: Finnish Centre for Pensions, 2008.

21 Carpenter JS, Andrykowski MA. Psychometric evaluation of the Pittsburgh sleep quality index. J Psychosom Res 1998;45:5-13.

22 Gentili A, Werner DK, Kuchibhatla M, et al. Test-Retest reliability of the Pittsburgh sleep quality index in nursing home residents. J Am Geriatr Soc 1995;43:1317-8.

23 Bech P, Rasmussen NA, Olsen LR, et al. The sensitivity and specificity of the major depression inventory, using the present state examination as the index of diagnostic validity. J Affect Disord 2001;66:159-64.

24 Bush K, Kivlahan DR, McDonell MB, et al. The audit alcohol consumption questions (AUDIT-C). Arch Intern Med 1998;158:1789-95.

25 Aalto M, Tuunanen M, Sillanaukee P, et al. Effectiveness of structured questionnaires for screening heavy drinking in middle-aged women. Alcohol Clin Exp Res 2006;30:1884-8.

26 Tuunanen M, Aalto M, Seppä K. Binge drinking and its detection among middle-aged men using audit, AUDIT-C and AUDIT-3. Drug Alcohol Rev 2007;26:295-9.

27 Yang X, Ge C, Hu B, et al. Relationship between quality of life and occupational stress among teachers. Public Health 2009;123:750-5.

28 Lerner DJ, Levine S, Malspeis S, et al. Job strain and healthrelated quality of life in a national sample. Am J Public Health 1994;84:1580-5.

29 Knudsen HK, Ducharme LJ, Roman PM. Job stress and poor sleep quality: data from an American sample of full-time workers. Soc Sci Med 2007;64:1997-2007.

30 Chen W-Q, Wong T-W, Yu T-S. Influence of occupational stress on mental health among Chinese off-shore oil workers. Scand J Public Health 2009;37:766-73.

31 Kivimäki M, Pentti J, Ferrie JE, et al. Work stress and risk of death in men and women with and without cardiometabolic disease: a multicohort study. Lancet Diabetes Endocrinol 2018:6:705-13.

32 LeBlanc M, Beaulieu-Bonneau S, Mérette C, et al. Psychological and health-related quality of life factors associated with insomnia in a population-based sample. J Psychosom Res 2007;63:157-66.

33 Reimer MA, Flemons WW. Quality of life in sleep disorders. Sleep Med Rev 2003;7:335-49.

34 Liu L, Fiorentino L, Rissling M, et al. Decreased health-related quality of life in women with breast cancer is associated with poor sleep. Behav Sleep Med 2013;11:189-206.

35 Liu J-C, Hung H-L, Shyu Y-K, et al. The impact of sleep quality and daytime sleepiness on global quality of life in community-dwelling patients with heart failure. J Cardiovasc Nurs 2011;26:99-105.
36 Palhares V de C, Corrente JE, Matsubara BB. association between sleep quality and quality of life in nursing professionals working rotating shifts. Rev Saude Publica 2014;48:594-601.

37 Nena E, Katsaouni M, Steiropoulos P, et al. Effect of shift work on sleep, health, and quality of life of health-care workers. Indian $J$ Occup Environ Med 2018;22:29-34

38 Lallukka T, Kaikkonen R, Härkänen T, et al. Sleep and sickness absence: a nationally representative register-based follow-up study. Sleep 2014;37:1413-25.

39 Lian Y, Xiao J, Liu Y, et al. Associations between insomnia, sleep duration and poor work ability. J Psychosom Res 2015;78:45-51.

40 Jedryka-Góral A, Bugajska J, Łastowiecka E, et al. Work ability in ageing workers suffering from chronic diseases. Int J Occup Saf Ergon 2006;12:17-30.

41 Kroes M, Osei-Assibey G, Baker-Searle R, et al. Impact of weight change on quality of life in adults with overweight/obesity in the United States: a systematic review. Curr Med Res Opin 2016;32:485-508.

42 Bridger RS, Bennett Al. Age and BMI interact to determine work ability in seafarers. Occup Med 2011;61:157-62.

43 Andersen LL, Izquierdo M, Sundstrup E. Overweight and obesity are progressively associated with lower work ability in the general working population: cross-sectional study among 10,000 adults. Int Arch Occup Environ Health 2017;90:779-87.

44 Mielck A, Reitmeir P, Vogelmann M, et al. Impact of educational level on health-related quality of life (HRQL): results from Germany based on the EuroQol 5d (EQ-5D). Eur J Public Health 2013;23:45-9.

45 Martimo K-P, Varonen H, Husman K, et al. Factors associated with self-assessed work ability. Occup Med 2007;57:380-2.

46 Pohjonen T. Perceived work ability of home care workers in relation to individual and work-related factors in different age groups. Occup Med 2001;51:209-17.

47 Koskinen S, Lundqvist A, Ristiluoma N. Terveys, toimintakyky ja hyvinvointi Suomessa 2011, 2012. Available: http://www.julkari.fi/ bitstream/handle/10024/90832/Rap0682012 netti.pdf? sequence $=1$

48 Michelson $\mathrm{H}$, Bolund $\mathrm{C}$. Health-Related quality of life measured by the EORTC QLQ-C30: reference values from a large sample of the Swedish population. Acta Oncol 2002;39:477-84.

49 Hult M, Pietilä A-M, Koponen P, et al. Association between good work ability and health behaviours among unemployed: a crosssectional survey. Appl Nurs Res 2018:43:86-92.

50 Saarni SI, Suvisaari J, Sintonen H, et al. Impact of psychiatric disorders on health-related quality of life: general population survey. Br J Psychiatry 2007;190:326-32.

51 Alonso J, Angermeyer MC, Bernert S, et al. Use of mental health services in Europe: results from the European study of the epidemiology of mental disorders (ESEMeD) project. Acta Psychiatr Scand Suppl 2004;109:47-54.

52 da Rocha NS, Power MJ, Bushnell DM, et al. The EUROHIS-QOL 8-item index: comparative psychometric properties to its parent WHOQOL-BREF. Value Health 2012;15:449-57.

53 Elinson L, Houck P, Marcus SC, et al. Depression and the ability to work. PS 2004;55:29-34.

54 Isometsä E, Kinnunen E, Kivekäs T, et al. Depression current care guidelines. Working group set up by the Finnish medical Society Duodecim and the Finnish psychiatric association. Finnish Curr Care Guidel 2016

55 Linton SJ, Kecklund G, Franklin KA, et al. The effect of the work environment on future sleep disturbances: a systematic review. Sleep Med Rev 2015;23:10-19.

$56 \mathrm{Li}$ CY, Sung FC, Sung E. A review of the healthy worker effect in occupational epidemiology. Occup Med 1999;49:225-9.

57 Shih T-H, Fan X. Comparing response rates in e-mail and paper surveys: a meta-analysis. Educ Res Rev 2009;4:26-40.

58 Vuorio T, Suominen S, Kautiainen $\mathrm{H}$, et al. Determinants of sickness absence rate among Finnish municipal employees. Scand J Prim Health Care 2019;37:3-9.

59 Porin kaupunki Henkilöstöraportti 2015, 2015. Available: https:// docplayer.fi/28278945-Porin-kaupunki-henkilostoraportti-2015.html

60 Kouvonen A, Kivimäki M, Väänänen $A$, et al. Job strain and adverse health behaviors: the Finnish public sector study. J Occup Environ Med 2007;49:68-74

61 El FM, Bocquet V, Majery N, et al. Work ability assessment in a worker population : comparison and determinants of Work Ability Index and Work Ability score. BMC Public Health 2013;13:1-10.

62 Kinnunen U, Nätti J. Work ability score and future work ability as predictors of register-based disability pension and long-term sickness absence: a three-year follow-up study. Scand J Public Health 2018:46:321-30. 